\title{
ETNOGRAFÍA Y PAISAJE SONORO. REVISIÓN METODOLÓGICA DE TRES PROYECTOS DE INVESTIGACIÓN: VALLE DE AZAPA E ISLA MOCHA
}

\author{
Andrés Mario Fortunato Mankoch ${ }^{1}$ \\ César Ignacio Borie Cervellino ${ }^{2}$
}

\section{Introducción}

De manera espontánea la presentación que da origen a este escrito adquirió una estructura que se asemeja a una experiencia de trabajo de campo, comenzando por aquel cúmulo de lecturas, expectativas y conceptos que nos alentaron y acompañaron en el viaje al encuentro de lo que definimos de antemano como nuestra temática de estudio, seguido por el enfrentamiento de estos conceptos de gabinete a las particulares realidades observadas desde la etnografía, para terminar con el regreso a casa, el replanteamiento reflexivo de los problemas derivados de la experiencia en terreno y las nuevas lecturas y conceptos a las que esta reflexión nos encaminó.

Hemos querido conservar esta estructura en la redacción del presente artículo para ilustrar de mejor forma aquel nunca cerrado viaje de ida y vuelta que significa hacer etnografía, profundizando en este caso en las particulares experiencias procedentes de tres proyectos de investigación con el fin de explorar las potencialidad del registro -en terreno-, elaboración -en estudio- y uso -en los artefactos fruto de los anteriormente mencionados proyectos-, de los paisajes sonoros para la construcción de significados y representaciones.

Para llevar a cabo este propósito se plantea el estudio de los paisajes sonoros incorporados en estos tres proyectos, segregándolos con fines analíticos del todo integrado que representa el soporte físico final de presentación para cada investigación, artefacto que corresponde a un dispositivo textual-gráfico-sonoro que denominamos gaceta etnográfica.

Se propone en este artículo un camino alternativo para conducir a la reflexión y análisis del uso de paisajes sonoros en etnografía, el cual se traza basándose en la discusión crítica que desde la segunda mitad del siglo XX ha suscitado en la disciplina antropológica la incorporación de medios visuales -imagen fija y en movimiento- en el trabajo de campo etnográfico. Este ejercicio hermana así imagen y sonido al considerarlos como medios de representación cuyo potencial es posible explorar en conjunto gracias a la incorporación crítica en antropología de nuevas formas de construcción en las narrativas etnográficas, derivadas en gran medida de cambios paradigmáticos y

\footnotetext{
${ }^{1}$ AZAPA Producciones Ltda, Chile.

${ }^{2}$ AZAPA Producciones Ltda, Chile.
} 
conflictos epistemológicos que desde fines de la década de 1980 se vienen dando en el campo de las ciencias sociales.

\title{
Etnografía
}

\begin{abstract}
Nosotros estudiamos la cultura en todas partes y donde sea que podamos, nuestra preocupación última es con las personas, con representar de manera adecuada y evocadora su mundo de experiencia, sus voces, su humanidad. (Feld, 1994:1).
\end{abstract}

Con esta frase de Steven Feld podemos resumir nuestra actitud inicial, y sostenida hasta hoy, al adentrarnos en el estudio de contextos y prácticas culturales específicas, actitud que trasluce la intención de este acercamiento y el interés por derivar de él un resultado capaz de transmitir, evocando y representando, aquellos personajes y lugares que dan vida a los fenómenos que intentamos estudiar.

Se vuelve necesario en esta empresa recurrir a formas más recientes de construir etnografías, enmarcadas dentro de estrategias de trabajo de carácter colaborativo, mejor adaptadas para relevar la multivocalidad que se hace evidente en la diversidad de discursos, acciones y motivaciones puestas en juego por los actores sociales. Por otra parte, se remarca la preocupación y el trabajo que se ha de dedicar a la elaboración de un adecuado dispositivo para la presentación de los resultados de este tipo de aproximación etnográfica reflexiva y multiautorial.

El trabajo colaborativo, en nuestro caso, hace referencia al esfuerzo mancomunado, en terreno y en gabinete, de un equipo conformado por un investigador de campo, un cineasta, un arqueólogo y un ingeniero en sonido, todos interiorizados, con profundidades diversas, en la etnografía y la producción fonográfica. Como hemos señalado anteriormente con respecto a este tipo de aproximación, el manejo de la técnica es un requisito ineludible. Tecnología contiene techne (arte, habilidad) y logos (argumento, idea), no pueden disociarse en distintas personas la técnica y la abstracción, es responsabilidad del antropólogo prepararse en estas áreas si desea sacar el mejor provecho de las tecnologías puestas a su disposición en la actualidad (Borie et al., 2006:20).

Con esto queremos destacar la doble necesidad, por un lado, de capacitación en el manejo de nuevas tecnologías y, por otro, de experiencia en terreno por parte de los integrantes del equipo de investigación.

El trabajo integrado en el abordaje de distintos temas que son resaltados y desarrollados de acuerdo a los intereses particulares de cada uno es, a su vez, lo que define nuestra forma de hacer etnografía como multiautorial, un acercamiento que con el paso del tiempo ha ido cristalizando en una estrategia de escritura de carácter reflexivo, donde se evidencian los investigadores en la construcción de relatos individuales, bajo la forma de apartados o capítulos de autoría personal, y en 
la presentación de material en bruto, extraído de los diarios de campo que circulan entre los miembros del equipo luego de finalizado el trabajo en terreno.

Por otra parte, fragmentos de entrevistas realizadas en terreno y luego transcritas, forman parte importante del producto final, entretejiéndose para construir una nueva narrativa que se presenta al lector como un recorrido temático. Coincidimos plenamente con Dicks y Mason en cuanto a que "la reflexividad no se trata de pretender que no hay diferencia entre las voces de los participantes y las de los autores; en cambio involucra reconocer y poner en evidencia el inevitable proceso de selección e interpretación que hacen de "la autoría" lo que es" (Dicks et al., 1998).

Lo que intentamos en nuestros trabajos es resaltar la multivocalidad e intersubjetividad involucradas en la producción de aquellos conocimientos que a través de la etnografía buscamos relevar. Al respecto, y en congruencia con la línea de argumentación arriba presentada, hemos señalado anteriormente que por medio de este ejercicio escritural no pretendemos diluir nuestra autoría al dar un protagonismo mayor a las voces de los informantes, sino que:

Estamos concientes de nuestra continua incidencia en su construcción y representación, desde el registro, pasando por el proceso de análisis y edición, hasta su presentación. [...] La autoría no es "superada" para dar paso a una absoluta libertad del público en la lectura e interpretación del material presentado. Sino que está presente bajo la forma de un estilo particular de concebir/hacer/difundir etnografía (Borie et al., 2006:19-20).

En este sentido estamos de acuerdo con James Clifford en cuanto a que el representar diferentes voces termina confirmando la virtuosa orquestación final por parte del autor de todos los discursos incluidos en el texto (Clifford, 1988:50-51 en Dicks et al., 1998).

La anteriormente señalada naturaleza multivocal e intersubjetiva del objeto de estudio, sumada a la intención de hacer visibles y accesibles los resultados de la investigación tanto dentro de la misma comunidad como entre académicos y público interesado en general, nos ha llevado a desarrollar artefactos que son presentados como plataformas tangibles, denominadas gacetas etnográficas, que, inspiradas en la experimentación con soportes hipermediales, entremezclan diversos registros realizados en terreno con los frutos del trabajo en gabinete. De ahí la elección de un soporte doble, compuesto, por una parte por un libro con texto (relatos, fragmentos de entrevistas transcritas y diarios de campo) e imagen (fotografías e ilustraciones) y, por otra, por un $\mathrm{CD}$ de audio que contiene música, entrevistas y paisajes sonoros.

Este énfasis en el aprovechamiento e integración de diferentes medios se sustenta en la convicción compartida de que "el potencial para una práctica representacional más sofisticada se da en la posibilidad de combinar diferentes formas de representación en un mismo medio. Es en el cuidadoso y organizado montaje de los diferentes tipos de "data" donde el potencial para nuevos significados puede surgir" (Dicks et al., 1998). 
A su vez, el afrontar el trabajo de campo con la idea de ofrecer al lector/oyente una descripción densa del fenómeno estudiado, gracias a la integración en un mismo soporte de diferentes medios de representación, tiene la virtud metodológica de aportar mayor libertad al etnógrafo, esto al eludir parcialmente las limitaciones que la naturaleza del producto final impone a las etapas previas de investigación. En otras palabras, "las maneras en que los etnógrafos buscan representar sus investigaciones inevitablemente orienta su aproximación a los proyectos, las tecnologías usadas, su relación con los informantes y las experiencias y conocimientos que producen (Pink, 2001:142).

La conformación de nuestro equipo, los medios de registro utilizados, la forma de concebir el trabajo de campo y la elección del soporte destinado a la presentación de los resultados de la investigación, son entonces elementos cruciales que han configurado en el tiempo una manera particular de entender y hacer etnografía que, con la revisión e incorporación crítica de nuevas lecturas y experiencias, nos ha llevado a involucrarnos en el trabajo con paisajes sonoros.

\section{Proyectos de investigación, música y paisajes sonoros}

Una vez reseñadas las ideas guía, conceptos, resguardos y expectativas que acompañaron nuestras primeras incursiones como equipo en el trabajo de campo, es momento de adentrarnos en el ámbito de los paisajes sonoros, empresa en la que nos embarcamos inicialmente de manera intuitiva y exploratoria con el fin de posicionar auralmente al lector/oyente de nuestras etnografías, como una manera de contextualizar aquella información entregada en la gaceta etnográfica bajo la forma de texto e imagen, además de situar espacial y temporalmente aquellas expresiones musicales y relatos orales presentados como parte del CD de audio acompañante de cada gaceta elaborada.

Se vuelve necesario hacer antes una breve reseña de los proyectos de investigación que alimentan esta reflexión metodológica, iniciativas financiadas por fondos concursables del Consejo Nacional de la Cultura y la Artes del Gobierno de Chile, que significaron un franco acercamiento desde la memoria oral y las expresiones musicales locales a la experimentación en el campo de los paisajes sonoros. En este repaso se entregan a modo de ejemplo imágenes de los productos finales de estos trabajos y pistas de audio que compilan muestras del material sonoro que conforma el CD de audio de cada gaceta. 


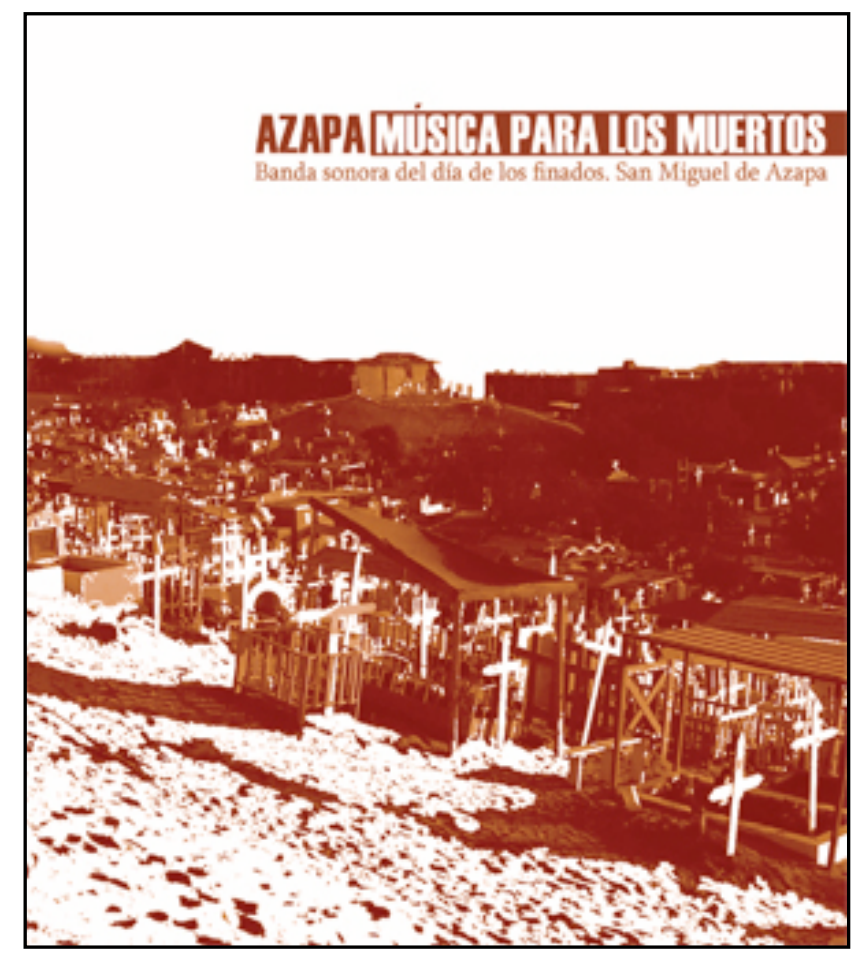

Carátula de la gaceta “Azapa. Música para los Muertos” (2006)

Con más bríos que conceptos, y luego de dos años de viajar a San Miguel de Azapa con propósitos documentales, emprendimos nuestro trabajo el año 2006 dentro del marco del proyecto “Azapa. Música para los Muertos", investigación destinada a indagar en la relación entre los deudos y la música, entendida esta última como una ofrenda entregada cada $1^{\circ}$ de noviembre en honor a los finados recientes en el cementerio de San Miguel de Azapa, ubicado $15 \mathrm{Km}$. al interior de la ciudad de Arica, en el extremo norte de Chile. Problemática específica que cristalizó luego de dos años de acercamiento etnográfico-audiovisual a la festividad y nos instó a mostrar la diversidad de estilos y formatos instrumentales que conviven durante aquel día en el cementerio. 


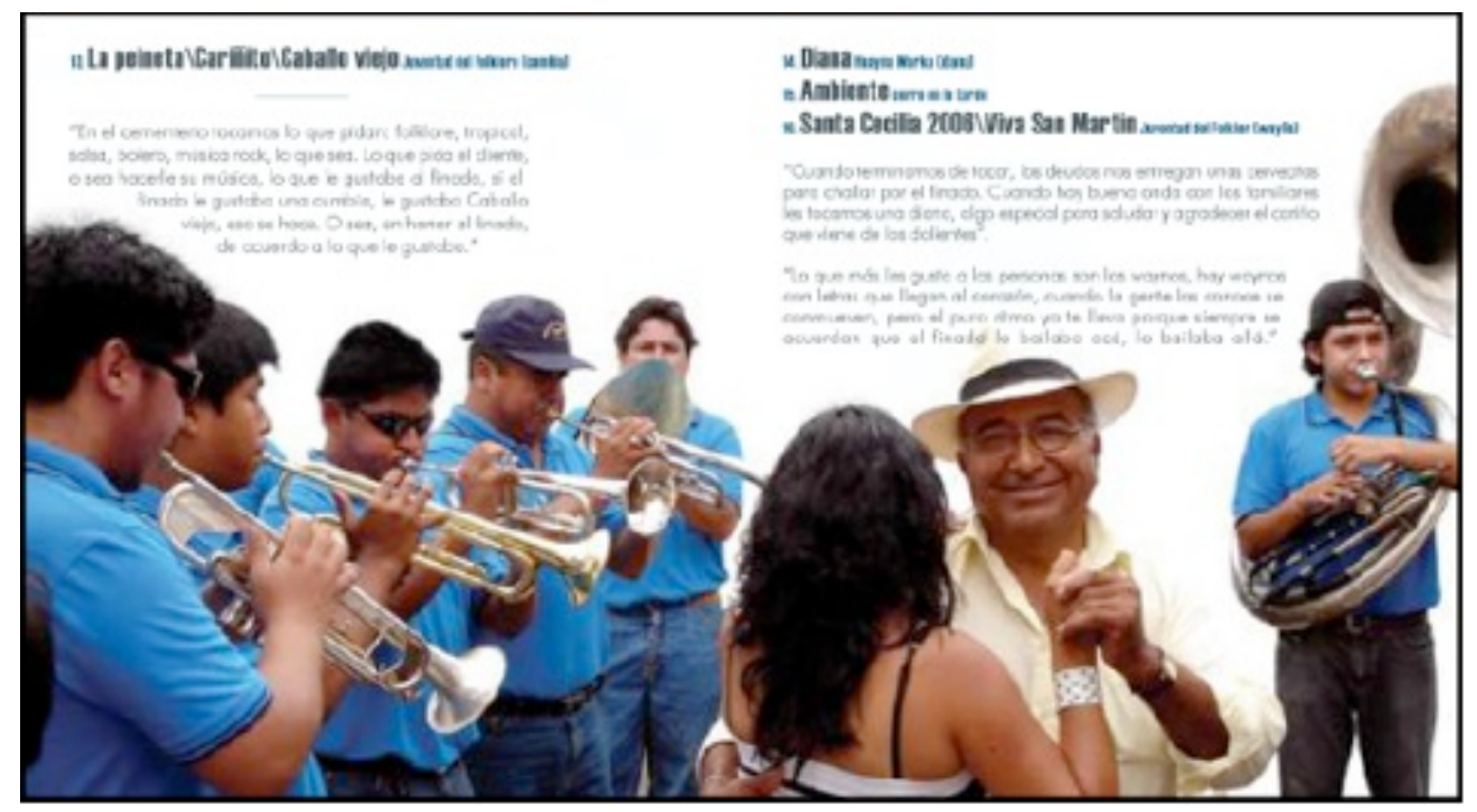

Detalle de páginas interiores de la gaceta “Azapa. Música para los Muertos” (2006) http://bievufrgs.blogspot.com/2010/07/blog-post.html

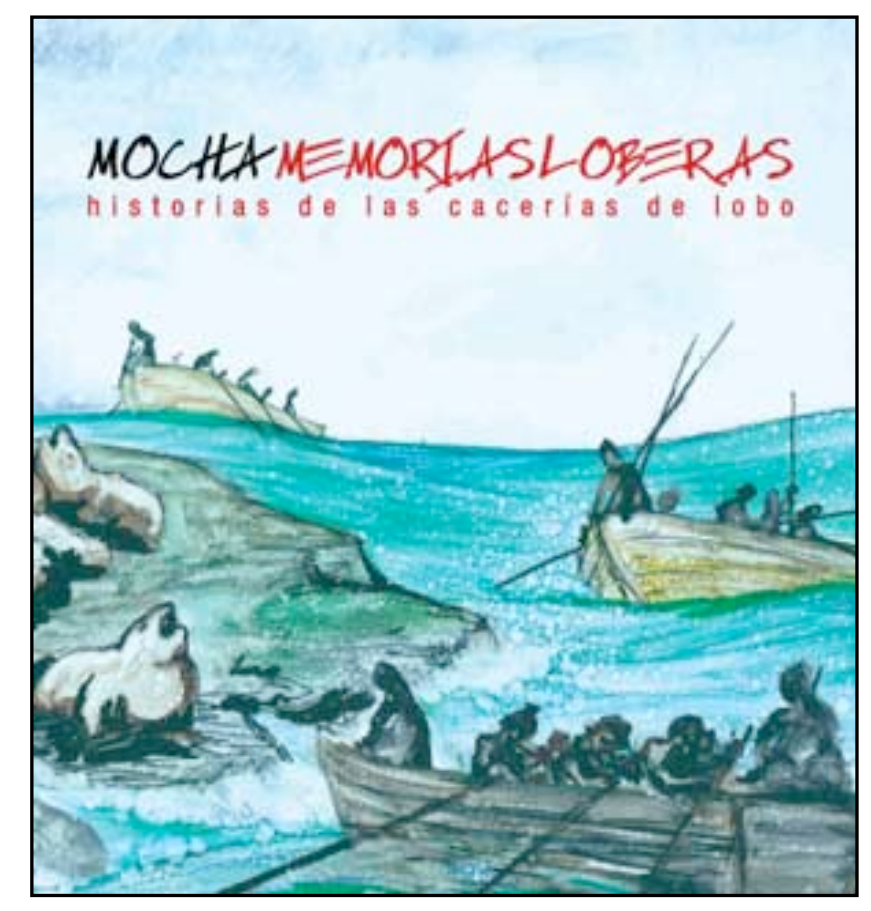

Carátula de la gaceta "Mocha. Memorias Loberas" (2007)

El año 2007, yendo obstinadamente tras los recuerdos de aquellos últimos hombres que participaron de masivas cacerías de lobos marinos en la isla Mocha, VIII Región, zona Centro-Sur de Chile, nos encontramos con registros de antiguas canciones entonadas por los mochanos que relataban, al ritmo de vals, cuecas y corridos, las peripecias de esta arriesgada empresa. Sorteando 
las dificultades que el paso los años, con el distanciamiento entre músicos y el abandono de los instrumentos tradicionales, imponía a esta tarea, logramos reunir a viejos músicos entre sí y con sus antiguos instrumentos para volver a revivir aquellas melodías que el tiempo iba borrando de a poco del recuerdo.

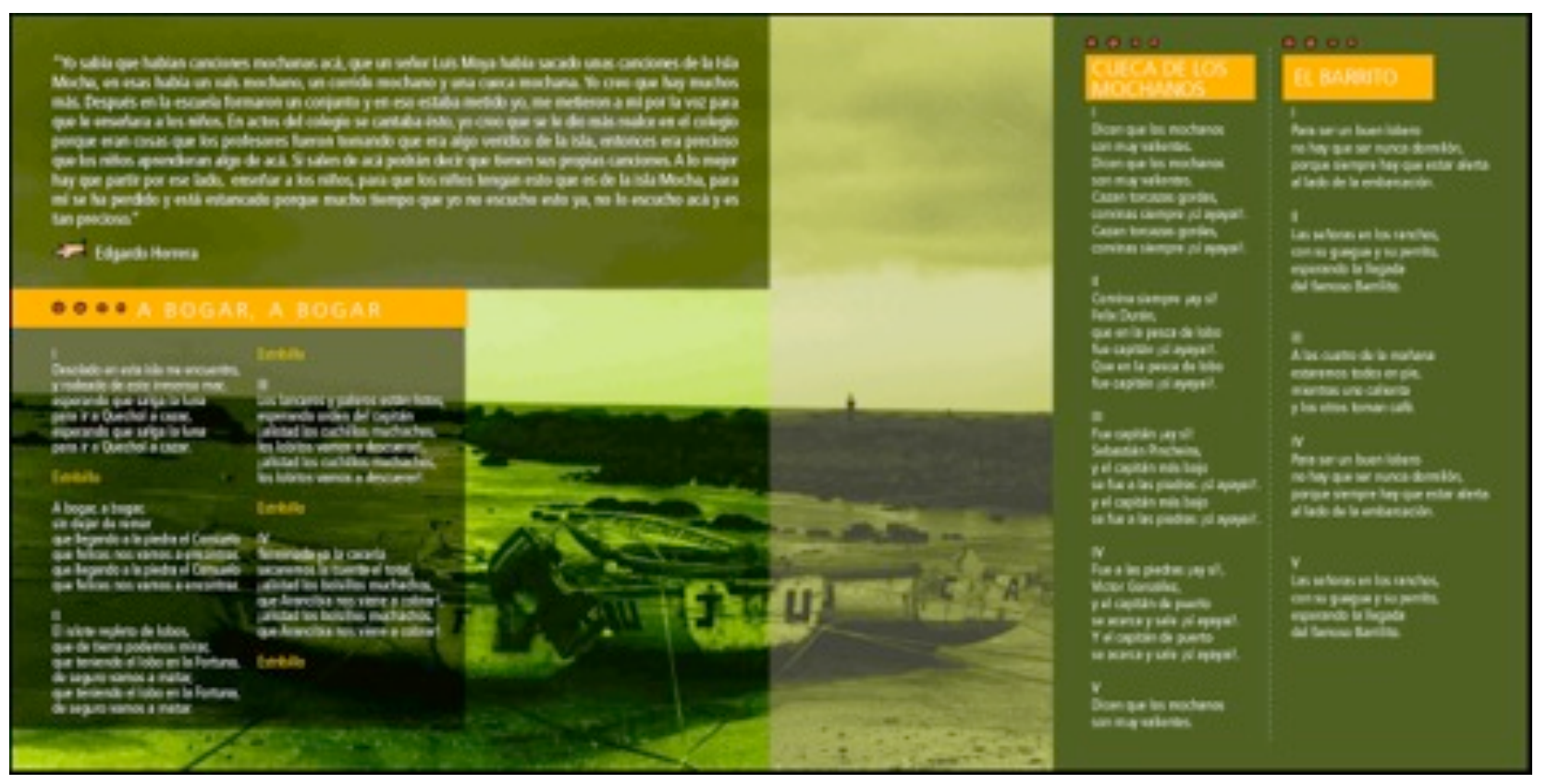

Detalle de páginas interiores de la gaceta "Mocha. Memorias Loberas” (2007)

http://bievufrgs.blogspot.com/2010/07/blog-post.html

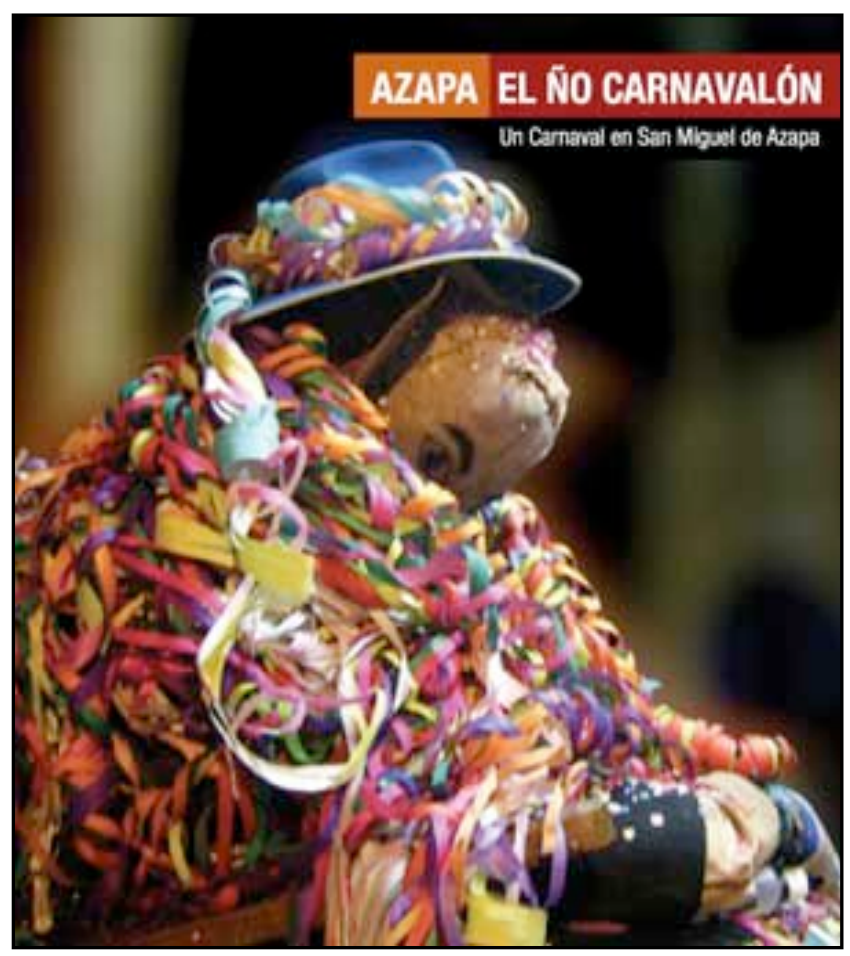

Carátula de la gaceta “Azapa. El Ño Carnavalón” (2008) 
Finalmente, el eterno ir y venir nos llevó de regreso el año 2008 a San Miguel de Azapa, esta vez con la exigente misión de hacer un seguimiento del Ño Carnavalón, muñeco antropomorfo portador de fertilidad y prosperidad, que se vuelve el foco y móvil de los festejos en este poblado nortino durante la semana de Carnavales, donde el infatigable sonido de las tarkas impulsa en largas jornadas a bailarines y seguidores en sus challas, sahumerios y rogativas al emblemático y poderoso personaje.

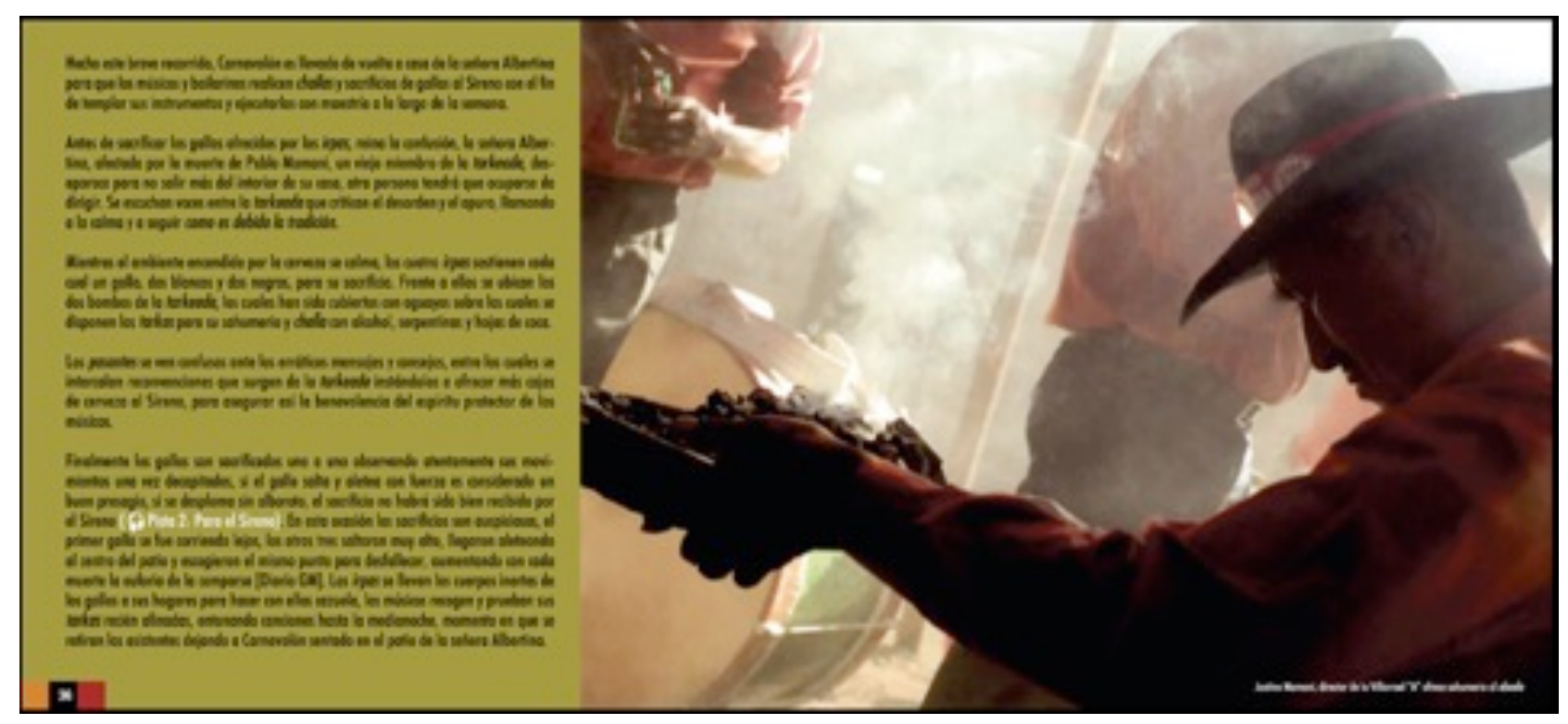

Detalle de las páginas interiores de la gaceta “Azapa. El ÑO Carnavalón” (2008)

\section{http://bievufrgs.blogspot.com/2010/08/etnografia-y-paisaje-sonoro-revision.html}

En esta secuencia de proyectos, la música pasó de ser la temática central de nuestros estudios, en el caso de "Azapa. Música para los Muertos"; a jugar un papel como acompañante de los vivos relatos ofrecidos por viejos loberos en "Mocha. Memorias Loberas"; y a convertirse en parte inseparable de aquellos ambientes sonoros que caracterizaban algunos de los hitos más relevantes de la celebración de Carnavales en “Azapa. El Ño Carnavalón”. Inversamente, los paisajes sonoros fueron cobrando relevancia y protagonismo, comenzando como un recurso ilustrador y contextualizador de las manifestaciones musicales y relatos orales presentados, a tomarse por completo el soporte de audio, posicionándose como verdaderos marcadores sonoros de algunos de los momentos más relevantes del Carnaval azapeño.

\section{Paisajes Sonoros}

Todo comienza cuando, armados con un equipo portátil de audio digital (TASCAM HD-P2) 
y un juego de micrófonos, nos lanzamos al registro en terreno orientados por la amplia definición que nos aporta Murray Schafer de paisaje sonoro como "toda porción del entorno sonoro considerada como un campo de estudio" (Schafer, 1977) e inspirados por la consigna de rescate, propuesta como uno de los objetivos primordiales del World Soundscape Proyect (WSP), originado en la Universidad Simon Frazer de Vancouver, Canada, en el sentido resaltado por Barry Truax, de documentar y archivar paisajes sonoros con el fin de promover una mayor conciencia del entorno sonoro a través de la escucha y el pensamiento crítico (Truax, 2002).

Siguiendo la noción de un continuo en la práctica de la composición de paisajes sonoros entregada por Truax $(2002 ; 2008)$ que va desde el "sonido fundado" (found sound), con un énfasis en el uso de paisajes sonoros nula o mínimamente procesados, hasta aquellos trabajos que optan por una mayor manipulación y abstracción de los sonidos (abstracted sound), nuestro uso de paisajes sonoros debe situarse dentro de este espectro, sin dudas, más próximo al "sonido fundado". De esta manera nuestras expectativas en el registro y composición de paisajes sonoros apuntaron desde un comienzo a facilitar, con técnicas de registro de alta fidelidad y un proceso de edición simple, el reconocimiento claro por parte del oyente de los sonidos y sus asociaciones contextuales originales, brindando a lo sonoro la mayor naturalidad y autonomía posible, esto último en cuanto a su relativa independencia respecto a la información contenida en el dispositivo gráfico y textual de la gaceta.

El registro en terreno se centró, siguiendo con las categorías entregadas por Truax (2002), en el aprovechamiento de una serie de perspectivas espaciales fijas que enfatizaban el flujo del tiempo al mostrar una secuencia de distintos momentos capturados desde diferentes puntos de observación/escucha.

Distanciándonos por un momento del ámbito de los paisajes sonoros, tal como fueron definidos por los miembros del WSP, y acercándonos al campo de la antropología, nos apoyamos en la idea que Feld resalta de Schafer (1977) referida a que una etnografía debe incluir lo que la gente escucha cada día (Feld, 2004). Con esto encontramos las directrices para liberar la tarea de registro sonoro de un sesgo exclusivamente estético y/o musical, y profundizar en la significación de los sonidos, naturales o culturales, que forman parte del entorno cotidiano de las personas a quienes se dirige nuestro estudio. La investigación y registro no se encasilla así en la materialidad acústica del sonido, para cuyo estudio se recurre tradicionalmente a categorías musicales occidentales, sino que hace indisociable a esta materialidad de los aspectos relativos a la vida social del sonido, sus dinámicas de producción y recepción, postura de Feld que recuerda la vieja consigna de John Blacking de indagar en la relación que la producción musical, su ejecución y recepción guardan con el medio particular en que se desarrollan, con su contexto sociocultural abordado desde una perspectiva etnográfica (Blacking, 1973).

De forma intuitiva, trabajamos en el proyecto “Azapa. Música para los Muertos” con 
paisajes sonoros capturados a lo largo de la celebración del Día de Finados en el poblado de San Miguel de Azapa, posicionando nuestros micrófonos dentro del cementerio en distintos momentos que cubren una progresión desde las tranquilas primeras horas de la mañana hasta la estridente yuxtaposición de sonidos producidos por deudos, visitantes y conjuntos musicales hacia el final del día. Estas pistas de paisajes sonoros fueron luego recortadas e intercaladas en el tracklist del CD de audio que acompañaba el texto de la gaceta etnográfica como un recurso para situar espacial y temporalmente al lector/oyente, aportando de esta manera un contexto festivo que transmitiera la sensación de "en vivo" a las piezas musicales que, por fines técnicos, fueron registradas en estudio con agrupaciones musicales de diversos formatos instrumentales que participan regularmente ejecutando sus temas el Día de Finados.

En este trabajo texto (librillo con fotografía) y audio (CD), si bien vinculados en el soporte material de la gaceta etnográfica, tienen la cualidad de funcionar también de manera independiente, en gran medida gracias al énfasis musical que anima a la obra sonora. Los paisajes sonoros aportan, además de la sensación de temporalidad (mostrando el transcurso de la fiesta) y especialidad (perspectivas desde el interior del cementerio y calles aledañas), continuidad y fluidez a las expresiones musicales registradas en estudio, al conformar una narrativa lineal que, empleando una secuencia de perspectivas fijas de captura sonora, transmite el dinamismo que la afluencia de público y la progresiva yuxtaposición de conjuntos musicales da al cementerio en esta celebración. En "Mocha. Memorias Loberas", el foco del registro sonoro se centra en los relatos aportados por antiguos mochanos acerca de las últimas cacerías masivas de lobos marinos que tuvieron lugar en la isla hacia finales de la década de 1950. A través del entrecruzamiento de estos vívidos y emotivos relatos se estructura una narrativa lineal y multivocal que abarca desde los preparativos de la cacería hasta la elaboración y comercialización de sus productos.

Los paisajes sonoros se hayan presentes dentro de este trabajo como un elemento evocador que sitúa espacialmente y va hilando los relatos de los loberos, resaltando aquellos sonidos que a lo largo de nuestra investigación se fueron posicionando como ambientes clave para ilustrar la geografía natural y cultural en la que se desarrolló una parte hoy perdida del modo de vida mochano, asimilables a soundmarks en la terminología de Truax (2008). A esta actividad de cacería llena de orgullo y nostalgia, aluden las líricas de las canciones que nos fue posible registrar y con las cuales se cierra la obra.

En este caso la porción sonora de la gaceta (CD de audio) se presenta como una capa de información anexa, más que complementaria, al texto, pues se produce una redundancia en los contenidos que dificulta la escucha y lectura simultánea. El riesgo que acarrea la mayor autonomía conseguida en el componente sonoro es la dificultad para mantener exclusivamente por esta vía una escucha atenta a lo largo de toda la obra, debido a que la sucesión de relatos se entrega de manera 
muy extensa, densa e imbricada, desorientando y cansando al oyente.

Los paisajes sonoros, representados por capturas de sonidos de las olas rompiendo en la playa, lobos marinos, paso de carretones, aves silvestres y de corral, entre otros, se integran dentro del tracklist que conforma el CD de audio entremezclándose con las locuciones de los loberos, marcando quiebres y pausas en el relato o funcionando como trasfondo (o keynote siguiendo a Truax, 2008) que remarca la distinción entre los diferentes personajes entrevistados, distinción que es reforzada empleando técnicas de paneo del sonido que sitúan al oyente en diferentes perspectivas al enfrentar el relato de los distintos loberos con los que tuvimos la oportunidad de hablar.

Finalmente en el trabajo "Azapa. El Ño Carnavalón”, se consagra a un registro sonoro, musical y situacional o performático, realizado con la intención de ofrecer al lector/oyente una imagen vívida del carnaval azapeño a través de la captura de momentos clave de semana de celebración. Los hitos del carnaval registrados fueron seleccionados luego de haber participado del carnaval en los años previos, el acceso a los lugares más íntimos de la celebración se consiguió gracias a la cercanía del equipo con la familia Flores Felipe, encargada de cuidar del abuelo Carnavalón, y a la amistad, paciencia y cariño desplegado por los músicos y bailarines de la tarkeada Villarroel "A".

Siguiendo la línea editorial que anima el texto de la gaceta, los paisajes sonoros registrados pretenden posicionar en la escena al oyente, hacerlo partícipe de la acción mediante una escucha atenta de capturas de alta definición que ofrecen, desde una secuencia de perspectivas fijas, cuadros dinámicos en los que, por ejemplo, se realiza el sacrificio de gallos para conseguir la benevolencia del espíritu protector de los músicos, o se produce el encuentro en una calle de dos comparsas de músicos y bailarines con la consiguiente yuxtaposición del sonido de voces, bombos, platillos y tarkas.

A diferencia de los dos casos anteriores, en esta gaceta etnográfica el CD de audio, compuesto íntegramente por paisajes sonoros que representan hitos relevantes de la festividad, cumple de manera adecuada la función de acompañar sonoramente el contenido del texto, emulando las cualidades de un soporte hipermedial o hipervinculado. El énfasis narrativo está puesto en el texto, la porción sonora del trabajo se encuentra referida en éste como una manera de representar, desde una perspectiva vivencial, momentos puntuales del carnaval descritos en detalle en el texto. Por este motivo aunque, como en los casos anteriores, el audio posee cierta autonomía respecto al texto, ésta se da un grado menor debido a que para su adecuada comprensión se requiere de la guía entregada por el texto.

Posteriormente descubrimos cierto parentesco entre estas aproximaciones a las potencialidades de los paisajes sonoros y el trabajo realizado en Valdivia e Isla de Pascua (Chile) por Luis Barrie dentro del área de patrimonio, oralidad y paisaje sonoro, en el cual se indaga en la 
escucha de paisajes sonoros como un proceso de adaptación que permite jerarquizar señales sonoras y correlacionarlas, proceso culturalmente aprendido y ecológica e históricamente modelado que destaca la necesidad de realizar prospecciones de hitos sonoros guiados por la memoria y la oralidad local (Barrie, 2007). Pese a la orientación patrimonial y de memoria oral que nos emparenta con el proyecto de Barrie, nuestro objetivo siempre ha sido, en un sentido amplio, el de construir representaciones etnográficas evocadoras, recurriendo para ello a diversas herramientas y soportes, sin agotarse en la búsqueda y registro de paisajes sonoros. Más bien, los paisajes sonoros han cumplido, como hemos visto en los párrafos anteriores, diversos roles con el paso del tiempo, esto debido a la incorporación de nuevas experiencias y conceptos para la consecución de los objetivos propuestos por nuestros proyectos.

Como ya hemos señalado, en este caso, con la intención de facilitar el análisis y contribuir a la discusión metodológica, los paisajes sonoros de nuestros trabajos han sido artificialmente aislados de la unidad que representa la gaceta etnográfica y luego reintegrados a ésta con el fin de evaluar sus potencialidades de manera independiente y en relación a los otros medios de representación empleados en la construcción de nuestras etnografías.

Este recorrido por nuestras experiencias en la integración al trabajo de campo etnográfico de conceptos tomados de la antropología, etnomusicología y la ecología acústica, nos lleva en la actualidad a sentirnos más cercanos a la idea de una antropología del sonido, levantada por Feld en oposición a las restricciones y sesgos encarnados por la noción de antropología de la música, definiendo un campo de estudio que se distancia, por otra parte, de las connotaciones de otredad ligadas al prefijo "etno" en la etnomusicología (Feld, 1994) y al estudio acotado a sociedades etnográficas cerradas que este tradicionalmente supone (Pelinski, 1998).

Así es posible adentrarse en el ámbito de los paisajes sonoros desde una perspectiva más amplia y contingente, donde el foco de la pesquisa se desplaza de la música en sí al entorno natural y cultural en su relación dialógica a través del sonido. Cobran relevancia de esta manera experiencias aurales que tienen que ver con el posicionamiento espacial y temporal, el lenguaje, la música, las relaciones sociales y la memoria. El sonido se vuelve una manera de conocer el mundo, una acustemología (acustemology), y los paisajes sonoros, una forma de presenciar acústicamente lograda gracias a una inmersión intensa y sostenida en las experiencias locales (Feld, 2001).

\section{De la imagen al sonido}

En este apartado se traza el camino seguido en la búsqueda de referentes para una reflexión sobre el uso de paisajes sonoros en etnografía. Como una manera alternativa de abordar esta empresa, se toman prestadas referencias que surgen del análisis crítico que se ha dado dentro del campo de la etnografía visual desde la década del 90 sobre las potencialidades y restricciones de la 
imagen, fija y en movimiento, en el campo de las ciencias sociales, discusiones cuyo origen se encuentra arraigado en la crisis de la representación etnográfica de finales del siglo XX. Vital en esta empresa ha sido la lectura de la extensiva revisión ofrecida por Sarah Pink en su libro "Doing Visual Ethnography" (2001), sobre la incorporación crítica de medios visuales en la producción y representación de conocimientos derivados de experiencias etnográficas.

Para contribuir a la reflexión metodológica que propone este artículo, lo sonoro (en este caso representado por los paisajes sonoros) es asimilado, en un sentido amplio y extensivo, a lo visual, volviéndose términos intercambiables al ser planteados ambos, no como simples herramientas de registro con potencialidades diversas, sino como medios de representación esgrimidos en la construcción y transmisión de significado en las narrativas etnográficas.

El surgimiento de la "nueva etnografía" a fines de la década de 1980, pone sobre el tapete las falencias de los enfoques positivistas en su búsqueda de conferir realismo y cientificidad a las experiencias de campo dentro del marco de las ciencias sociales. La subjetividad adquiere así centralidad en el proceso de producción del conocimiento y con ello cobran protagonismo nuevas formas narrativas que dan cabida a lo visual, ya no como una prueba fidedigna del "estar allí" o como "data" objetiva, sino como una estrategia más dentro de aproximaciones reflexivas al trabajo de campo en las que experiencia, conocimiento y representación se ligan de manera indisoluble (Pink, 2001).

Siguiendo las ideas de Edwards (1997), sólo al abandonar las pretensiones de distancia, objetividad y generalización, es posible desarrollar las cualidades propias y potencialidades que la ambigüedad y expresividad de las imágenes visuales ofrecen a la etnografía. Consideramos esto aplicable también al caso del sonido y particularmente de los paisajes sonoros.

El reconocimiento de las etnografías como narrativas construidas o ficciones, en el sentido que le da Clifford de verdades parciales (Clifford et al., 1986), abre la senda a la incursión de los autores en nuevas técnicas de escritura reflexiva en etnografía, más apegadas a la experiencia y a lo particular, lo que, a su vez, crea un ambiente favorable para la inclusión de lo visual -y por extensión, de lo sonoro- en la representación etnográfica (Pink, 2001:10).

Estos cambios al interior de las ciencias sociales incluyen críticas a la concepción de la etnografía en términos de una narrativa lineal, que representa la experiencia etnográfica como "una actividad en la cual el etnógrafo va "al campo", recoge la "data" y luego regresa a "casa" a analizar y escribir" (Kulick 1995, citado en Pink, 2001:117).

Críticas similares se han hecho a la representación etnográfica por fallar en reconocer las realidades múltiples y simultáneas en las cuales las personas viven y participan, la intersubjetividad entre los etnógrafos y los "sujetos" de su investigación, y las diferentes voces, perspectivas y locaciones temporales y espaciales que la etnografía involucra (Pink, 2001:117). 
Como un camino para resolver esta problemática autores proponen la construcción de narrativas etnográficas siguiendo un principio de montaje, incorporando por esta vía la “multilinealidad de la investigación etnográfica de la vida cotidiana" (Marcus, 1995:41, citado en Pink, 2001:117), y destacando la necesidad de incorporar las epistemologías locales, personales y académicas en un mismo relato, sin establecer entre éstas ningún orden jerárquico ni recurrir a traducción de las visiones locales a los términos del discurso académico (Marcus, 1995, citado en Pink, 2001:117).

La técnica del montaje a su vez acoge distintas categorías de lo visual en una misma narrativa etnográfica, pudiendo coexistir en un mismo "texto" recursos de tipo realista con aquellos de carácter más expresivo, combinando la "frontalidad" de lo documental con la capacidad evocadora y sentido crítico que despierta lo expresivo y creativo (Edwards, 1997).

Por su parte, para hacerse cargo de esta premisa la imagen en movimiento es presentada, en contraste a la palabra escrita, como un medio portador de una mayor capacidad para evocar experiencias humanas gracias a su apego a lo particular y concreto..

Imagen en movimiento y la palabra escrita tienen el potencial de especializarse en diferentes elementos de lo general y lo específico $\mathrm{y}$, por ende, de representar distintos tipos de experiencias etnográficas y teorías. No se debe, por lo tanto, esperar que representen estos temas de la misma forma, ya que sus diferencias de hecho posibilitan que los etnógrafos aborden temas claves de diferentes maneras (Pink, 2001:144).

Creemos que esta capacidad exaltada para la imagen en movimiento es extrapolable al ámbito del sonido. Los paisajes sonoros remiten de manera evocadora a la audiencia a elementos y asociaciones simbólicas extraídas de -o, en el caso de aquellas composiciones de paisajes sonoros más abstractas, inspiradas en- fenómenos naturales o sociales que tienen lugar en locaciones y momentos específicos, ligando la experiencia aural del lector/oyente a situaciones puntuales y concretas del trabajo de campo.

No se trata, por ende, de privilegiar la utilización de un medio de representación por sobre otro, sino de trabajar desde:

Un enfoque reflexivo puede tomar ventaja de las diferentes maneras del video, fotografía y texto escrito para representar experiencias etnográficas, teoría y crítica. Combinando diferentes medios de representación etnográfica los investigadores pueden yuxtaponer diferentes tipos de conocimiento, subjetividad, epistemología y voz de manera que se complementes las unas a las otras". (Pink, 2001: 144)

La producción y uso de imágenes visuales investigaciones empíricas basadas en el trabajo de campo, deben ser entendidas como uno y sólo uno de los diversos métodos que el investigador social puede usar (Banks, 2001). Proponemos que se debe incluir dentro de estos medios de 
representación a lo sonoro como un recurso documental y expresivo que, en el marco de la elaboración de nuevas etnografías, sean estas presentadas como montajes textuales, ensayos fotográficos, films o plataformas hipermediales, tenga la capacidad de inspirar a los lectores/visores/auditores a cuestionar autoconciente y reflexivamente los contenidos y significados de las representaciones etnográficas. Aproximación crítica que puede ser desarrollada o guiada a gracias al manejo de nuevas formas narrativas (Mermin 1997, citado en Pink, 2001: 147).

\section{Los productos etnográficos y sus destinatarios}

Siguiendo con la línea argumental arriba propuesta, es necesario hacerse cargo de ciertas problemáticas que se vuelven evidentes con el empleo de estas nuevas estrategias y medios de representación en etnografía.

Se debe estar conciente de que el uso e interpretación que reciba una etnografía va a depender de la definiciones y conceptos que le otorga a ésta el propio autor y de las clasificaciones aportadas por aquellas personas que reciben su trabajo, sea éste el público general, los "sujetos" de investigación o la comunidad académica (Pink, 2001). La consideración de aspectos relacionados a las modalidades de consumo de la etnografía cobran así relevancia ya que, como hemos señalado más arriba al referirnos al soporte de presentación de las investigaciones, condicionan aspectos metodológicos, tecnológicos y sociales del trabajo de campo etnográfico.

Banks en sus reflexiones finales sobre el empleo de métodos visuales en la investigación social, detalla que:

La producción de imágenes por parte de investigadores sociales no puede ser entendida de manera separada del consumo de imágenes por todos -investigadores sociales, académicos en general y, por supuesto, de los mismos sujetos de la investigación social. Todas las imágenes visuales, sin importar su origen, son inherentemente problemáticas [...] pero a la vez son un aspecto omnipresente de casi todas las relaciones sociales humanas (Banks, 2001:177).

Defendemos que lo mismo es válido para el caso de lo sonoro, igualmente problemáticos al ofrecer múltiples lecturas que van desde su consideración como testimonio documental tangible hasta su recepción crítica como recurso expresivo, evocador y reflexivo. Tal como señalan Hockey y Dawson, "las representaciones una vez hechas están sujetas a re-representación, representaciones erróneas y apropiación” (Hockey et al., 1997:13, citado en Pink, 2001:116), tema especialmente delicado cuando se trabaja, como en nuestro caso, dentro del marco de proyectos de difusión que pretenden entregar contenidos accesibles tanto a los habitantes del lugar donde se lleva a cabo la investigación etnográfica, como a visitantes y turistas, además de poseer valor como material de estudio para la comunidad académica y especialistas en las ciencias sociales.

Esta situación plantea nuevos desafíos al etnógrafo quien, al igual que el creador de film 
etnográfico, debe estar conciente de su responsabilidad al "supervisar y dirigir las experiencias de su público en la lectura y creación de significado a partir de su obra" (Mermin 1997:49, citado en Pink, 2001:116). Lo cual exige el manejo, tanto por parte del etnógrafo como del público al que apunta, de convenciones de registro y edición que "no simplemente dirigen a diferentes puntos de vista [...], sino que orquestan un set yuxtapuesto de códigos de posición, narrativa, metáfora y postura moral” (MacDougall 1995:223, citado en Pink, 2001:146).

De esta manera se transfiere responsabilidad a los receptores de las etnografías bajo la forma de un llamado a una lectura crítica, a no tomar los contenidos presentados como verdades en sí sino a entenderlos como representaciones que al ser observadas autoconciente y reflexivamente nos brindan significado (Pink 2001).

\section{Oyendo etnografías}

Desafortunadamente no disponemos de estudios específicos sobre la manera en que las etnografías que en diversos grados utilizan el sonido, son recibidas por las audiencias académicas y extra-académicas, lo que nos enfrenta a la imposibilidad de saber con certeza como una actividad tan individual y personal como es hacer etnografía sonora, es experimentada por otros. Sin embargo, las reflexiones de MacDougall sobre la recepción de films etnográficos pueden ofrecernos ciertas pistas ya que llevan a este autor a afirmar que "el "significado" de un film etnográfico no es inherente al film en sí, ni a las intenciones de el (o los) autor(es), sino que es una propiedad negociable que se ubica en el triángulo conceptual formado por el sujeto (del film), el creador del film y la audiencia” (MacDougall 1978: 422, citado en Banks, 2001:140).

En el caso de aquellos trabajos etnográficos que otorgan autonomía al sonido, esta negociación y construcción de significado se da en un contexto moderno y global donde:

El desarrollo continuo en las tecnologías de grabación y reproducción ha llevado a los consumidores a esperar mayor calidad y claridad en el sonido. Incluso más que en las performances presentacionales, la grabación de sonidos por si solos acarrea el peso de sostener la atención y el interés. Más aún, el sonido presentado tiene que resistir escuchas reiteradas; este hecho requiere un tipo diferente de atención detallada al sonido presentado e influencia los procesos de selección, mezcla y edición (Turino, 2008:70)

Estas exigencias al creador de etnografías sonoras encuentran su contraparte en una audiencia en gran medida familiarizada con situaciones de escucha "esquizofónicas" (schizophonic), en las que se produce una yuxtaposición de sonidos y es posible elegir un entrono sonoro en el cual sumirse mediante el uso de radios y reproductores de audio personales, a lo que se suma el entrenamiento perceptual que significa la experiencia cotidiana con secuencias cinematográficas y técnicas de montaje audiovisual (cross-fade, jump cuts, etc.), el manejo 
generalizado del lenguaje convencional de las bandas sonoras de películas y la incorporación de paisajes sonoros (realistas y fantásticos) desarrollados por la industria del video juego (Truax, 2002; 2008). Este contexto moderno de escucha ha redundado en que hoy "los oyentes son más competentes para decodificar múltiples integraciones de sonidos originados en una amplia variedad de tiempos y lugares mientras parezca haber un orden lógico en su combinación" (Truax, 2002). Siguiendo a Truax coincidimos en que:

Históricamente estos desarrollos tecnológicos involucran no solo la expansión del lenguaje del sonido electroacústico, sino también la expansión de las estrategias del oyente electroacústico en ambas direcciones dentro de un continuo de atención desde lo que he llamado escucha distraída (p.e, habituación a medios y música como entorno) hasta la escucha analítica (p.e. discernimiento de la cualidad de los sonidos, de una buena o mala reproducción, de parámetros separables del sonido y de la espectromorfología" (Truax, 2008).

Se vuelve pertinente en este momento detenernos brevemente en el trabajo de Ramón Pelinsky (2007), quien define varios tipos de escucha a partir del grado de atención que les brinda el auditor, lo cual a su vez condiciona la interpretación que éste deriva de los eventos sonoros. Tipos de escucha que servirán luego para indagar en el uso de paisajes sonoros como parte de nuestros proyectos etnográficos.

- Escucha natural: Tipo de escucha desenfocada y distraída. La atención se desliza por encima del sonido sin penetrar en su interior.

- Escucha natural - referencial e interactiva: Se habla de escucha referencial porque identifica el sonido con su génesis o con la fuente que lo produce, su posición. Por otra parte es interactiva porque integra la audición con la acción, la información auditiva específica controla y dirige la relación con el entorno.

- Escucha natural - simbólica: Tipo de escucha que toma un evento sonoro como índice, signo o símbolo de otra cosa.

- Escucha natural - ingenuamente realista: Escucha que considera que los procesos sonoros existen en sí, en un mundo separado de la conciencia, ignorando que los ruidos del entorno no son más que interpretaciones de datos auditivos.

- Escucha reducida: nos abre los oídos para despertar la sensación sonora de su reposar en sí, transformarla en percepción consciente y, si ello es posible, en escucha virtualmente musical.

En la revisión de nuestros trabajos notamos que estos tipos de escucha definidos por Pelinski pueden ser de diversas formas inducidos y manipulados dinámicamente mediante estrategias de composición y vinculación con otros sonidos o medios de representación. Así, por ejemplo, al leer el librillo del proyecto “Azapa. El Ño Carnavalón” mientras se escucha el disco a un volumen 
moderado, se puede lograr una escucha natural, que va de distraída a referencial, esto último cuando se hace hincapié en los hitos auditivos destacados en el texto, lo cual se distancia bastante de la escucha natural - realista que se insinúa al oír el disco como un material separado del resto del artefacto.

Los paisajes sonoros de "Mocha. Memorias Loberas" pasan de ser referenciales a simbólicos, al marcar, por un lado, eventos sonoros que definen un lugar (soundmarks) y, por otro, al estar entrelazados con relatos orales emotivos que conducen al oyente a prestar atención a aspectos simbólicos y evocadores por sobre la estética y asociaciones naturales del contexto original de los sonidos. Lamentablemente la escucha atenta de este trabajo se torna difícil por su complejidad y extensión, enfrentando al auditor a una larga secuencia de relatos correspondientes a distintas voces registradas en diferentes locaciones, los que son luego hilados formando un nueva narrativa de estructura lineal.

Finalmente, en el caso de "Azapa. Música para los Muertos", se invita al oyente a una escucha del tipo natural referencial e interactiva que lo sitúa auralmente en el cementerio durante el transcurso de la celebración del día de los difuntos, pero, al hallarse estos paisajes sonoros entrelazados con piezas musicales, se provoca que la atención del oyente se dirija también a un tipo de escucha reducida que se enfoca en la estética del sonido en sí, en su musicalidad.

A modo de ejemplo, y experimento, nos hemos enfocado en la escucha natural simbólica para componer un paisaje sonoro a partir de los registros llevados a cabo en Isla Mocha. Siguiendo como guía las obras sonoras de Truax, seleccionamos keynotes (o sonidos pedales) para caracterizar la geografía del lugar. Los soundmarks (o marcas sonoras) por su parte, fueron relevados durante el trabajo de campo etnográfico y seleccionados por su significación cultural. Los paisajes sonoros fueron luego montados y procesados de manera de crear una perspectiva de movimiento espacial a partir de una secuencia de perspectivas fijas de registro.

\section{http://bievufrgs.blogspot.com/2010/08/etnografia-y-paisaje-sonoro-revision.html}

\section{Palabras finales}

La integración de diferentes medios de registro y representación en nuestras etnografías se dirige a entregar un tipo de descripción densa de los fenómenos particulares que son observados en el proceso de investigación y objeto de reflexión posterior, no se pretende con ello transmitir, gracias al cúmulo de detalles culturales específicos entregados, una apariencia de verdad a estos textos (Geertz, 1989:13).

La construcción de este tipo de etnografía descansa en la idea de que "las imágenes visuales, objetos y descripciones", a lo cual sumamos los sonoro, "deben ser incorporadas cuando es 
apropiado, oportuno y esclarecedor hacerlo" (Pink, 2001:5).

En este caso en particular, lo sonoro se resiste a funcionar adecuadamente como un soporte autónomo, pues, como ya hemos señalado, nuestra intención siempre tuvo en vista su articulación con otros medios de representación que incluyen lo textual y lo gráfico dentro de la unidad integrada que representa la gaceta etnográfica en que entregamos los resultados de nuestras investigaciones. Los paisajes sonoros son presentados en estos trabajos con diversos énfasis e intenciones que incluyen, entre otros, su uso como elemento vinculante entre piezas musicales o relatos orales, como recurso ilustrador o contextualizador que posiciona auralmente al lector/oyente en el momento y lugar en que se desarrolló el trabajo de campo, como registro documental o material de investigación para futuros análisis.

El ejercicio de aislar el componente sonoro de estas etnografías y escudriñar en sus potencialidades empleando conceptos derivados de la antropología, etnomusicología, ecología acústica y del ámbito de la composición de paisajes sonoros, ha conducido sin embargo a reflexiones que, apoyándose en discusiones dadas al interior de las ciencias sociales en torno a la incorporación de la imagen fija y en movimiento, destacan a lo sonoro como un recurso expresivo que, gracias a su arraigo a experiencias vividas en contextos particulares, a su poder evocador y a la ambigüedad que acarrea su posible lectura en un espectro que va desde el dato concreto al constructo artístico, cualidad esta última que pone en evidencia la "inevitabilidad de no poder comprender todo, desafiando los llamados de autoridad y "verdad" que encarnan las aproximaciones realistas a los "textos" etnográficos (Edwards, 1997:75). Todo esto sin dejar de lado su validez como un campo de investigación en sí (antropología del sonido y ecología acústica) y como fuente de inspiración (p.e. en la composición de paisajes sonoros) que se halla indefectiblemente en nuestro entrono cotidiano, haciendo dialogar de múltiples maneras lo natural y lo humano.

Concordamos con la aseveración de Pink de que "nuevas formas de representación implican nuevas prácticas de lectura etnográfica" (Pink, 2001:127). Posicionando a lo sonoro dentro de las estrategias de construcción narrativa en etnografía, desarrolladas desde finales de la década del 80, es como podemos conseguir explorar de manera más profunda sus potencialidades como transmisor de significados e indagar en su afinidad con otros medios de representación integrados dentro de un mismo soporte, sea éste físico o hipermedial.

Tomar esta postura acarrea nuevas exigencias y desafíos a los lectores/visores/oyentes de etnografía, constituyendo un llamado a la construcción crítica de significado a partir de las representaciones que son entregadas en diversos soportes y con distintas finalidades por el investigador. Sin embargo, el manejo cada vez más masivo y global de códigos y convenciones procedentes del lenguaje cinematográfico y del mundo de los videojuegos, sumado a la irrupción 
continua de nuevas tecnologías sonoras en la vida cotidiana, favorece la acogida, tanto dentro como fuera del ámbito académico, de la experimentación en el campo de los paisajes sonoros.

La invitación es así a seguir explorando en el uso de recursos y soportes que contribuyan a comunicar de manera reflexiva y evocadora a un público cada vez más amplio, diverso y crítico, aquellos aspectos de la experiencia de campo que revelan la subjetividad, la negociación, la diversidad, el encuentro y los conflictos que forman parte integral de la investigación etnográfica.

\section{Referencias}

BANKS, M. Visual Methods in Social Research. SAGE Publications, Londres, 2001.

BARRIE, L., en Actas del Primer Encuentro Iberoamericano sobre Paisajes Sonoros [on line], Madrid, 2007 [fecha de consulta: 25 de septiembre de 2009]. Disponible en: http://cvc.cervantes.es/artes/paisajes sonoros/p sonoros01/barrie/barrie $01 . h t m$

Blacking, J. How musical is man?. University of Washington Press, Seattle y Londres, 1973.

BORIE, C., MORA, G. Azapa. Etnografía, Fiesta y Muerte, en Revista Chilena de Antropología Visual n ${ }^{\circ}$ 7, pp. 7-23, 2006. Disponible en: http://www.antropologiavisual.cl/borie \& mora.htm

CLIFFORD, J., MARCUS, G. Writing Cultures: The Poetics and Politics of Ethnography. Berkeley, University of California Press, 1986.

CLIFFORD, J. The Predicament of Culture: 20 Century Ethnography, Art and Literature. Cambridge MA. Harvard University Press, 1988.

DICKS, B., MASON, B. "Hypermedia and Ethnography: Reflections on the Construction of a Research Approach", en Sociological Research Online, vol. 3, nº 3, 1998. [fecha de consulta: 16 de febrero de 2005]. Disponible en: http://www.socresonline.org.uk/socresonline/3/3/3.html

EDWARDS, E. Beyond the Boundary: a consideration of the expressive in photography and anthropology, en M. Banks, H. Morphy (eds.), Rethinking Visual Anthropology. Londres, Routledge, 1997.

FELD, S. From Ethnomusicology to Echo-Muse-Ecology: Reading R. Murray Schafer in the Papua New Guinea Rainforest, en The Soundscape Newsletter, $\mathrm{n}^{\circ}$ 08, junio, 1994.

FELD, S. Doing anthropology in sound, en American Ethnologist, Noviembre 2004, vol. 31, $\mathrm{n}^{\mathrm{o}} 4$, pp. 461-474, 2004.

FELD, S. The Sound of Bosavi [on line], 2001 [fecha de consulta: 20 de septiembre de 2009]. Disponible en: http://www.acousticecology.org/edu/educurrbosavi.html\#Anchor-From-47857

GEERTZ, C. El antopólogo como autor. Ediciones Paidós, Barcelona, 1989.

HOCKEY, J., DAWSON, A. After Writing Culture: Epistemology and Praxis in Contemporary Anthropology, Londres, Routledge, 1997.

KULICK, D. The sexual life of anthropologists: erotic subjetivity and ethnographic work, en D. kulick, M. Willson (eds.), Taboo: Sex, Identity and Erotic Subjectivity in Anthropological Fieldwork, Londres, Routledge, 1995.

MACDOUGALL, D. The subjective voice in ethnographic film, en L. Devereaux, R. Hillman (eds.), Fields of Vision: Essays in Film Studies, Visual Anthropology and Photography. Berkeley: University of California Press, 1995.

MACDOUGALL, D. Ethnographic Film: failure and promise, en Annual Review of Anthropology, vol 7, pp. 405-425, 1978.

MARCUS, G. The modernist sensibility in recent ethnographic writing and cinematic metaphor of montage, en L. Devereaux, R. Hillman (eds.), Fields of Vision: Essays in Film Studies, Visual Anthropology and Photography. Berkeley: University of California Press, 1995.

MERMIN, S. Being Where? Experiencing narratives of ethnographic film, en Visual Anthropology Review, vol 13, no 1, pp 40-51, 1997.

PELINSKI, R. ¿Qué es etnomusicología?, en Actas del III Congreso de la SIbE. Barcelona, pp. 35- 
$56,1998$.

PELINSKI, R. "El oído alerta: modos de escuchar el entorno sonoro", en Actas del Primer Encuentro Iberoamericano sobre Paisajes Sonoros [on line], Madrid, 2007 [fecha de consulta: 25 de septiembre de 2009]. Disponible en: http://cvc.cervantes.es/artes/paisajes_sonoros/p sonoros01/pelinski/pelinski 01.htm

PINK, S. Doing visual ethnography. Images, media and representation in research. SAGE Publications, Londres, 2001.

SCHAFER, M. The Tuning of the World. Toronto, McClelland and Stewart, 1977.

Turino, T. Music as social life. The politics of participation, The University of Chicago Press, Chicago y Londres, 2008.

TRUAX, B. Genres and techniques of soundscape composition as developed at Simon Fraser University, en Organised Sound, vol 7, $\mathrm{n}^{\mathrm{o}}$ 1, pp. 5-14, 2002 [on line] [fecha de consulta: 22 de septiembre de 2009]. Disponible en: http://www.sfu.ca/ truax/OS5.html

TRUAX, B. Soundscape Composition as Global Music: Electroacoustic Music as Soundscape, en Organised Sound, vol 13, no 2, pp. 103-109, 2008 [on line] [fecha de consulta: 22 de septiembre de 2009]. Disponible en: http://www.sfu.ca/ truax/OS7.html 